\title{
Uso de animações para o ensino inclusivo de imunologia: uma experiência docente
}

\section{Use of animations for inclusive teaching of immunology: a tutoring experience}

\author{
Joanna de Freitas Rocha' \\ Letícia de Castro Viana ${ }^{2}$ \\ Erika Freitas Mota ${ }^{3}$
}

\section{Resumo}

Muitas pessoas vivem com algum tipo de deficiência visual e os professores necessitam buscar soluções para garantir a inclusão desses indivíduos no Ensino Superior. Baseado nisso, um modelo didático com vídeos animados inclusivos foi confeccionado e aplicado a uma turma de imunologia, durante o ensino remoto emergencial, como parte dos requisitos para aprovação da disciplina de estágio em docência e relatado neste trabalho. O material consistiu em três vídeos curtos, com narração, animações feitas em PowerPoint, legenda e áudio-descrição. Os alunos da disciplina de imunologia foram divididos em dois grupos para avaliar o material e a atuação da iniciante em docência através de formulários online: os que ouviram somente a áudio-descrição e os que viram os vídeos animados sem a descrição. Os alunos consideraram que o material auxiliou no aprendizado inclusivo e remoto de imunologia e a experiência de participar do aprendizado desses alunos foi de grande valia.

Palavras-chave: Vídeos. Deficiência visual. Áudio-descrição. Bactérias. Ensino remoto.

\begin{abstract}
Many people live with some type of visual impairment and teachers need to find solutions to ensure the inclusion of these individuals in Higher Education. Based on this, a didactic model with inclusive animated videos was made and applied to an immunology class, during emergency remote teaching, as requirement for the Internship to Teaching discipline approval and reported on this work. The material consisted of three short videos, with narration, PowerPoint animations, subtitles and audio description. The students of the immunology discipline were divided into two groups to assess the material and performance of the trainee teacher through online forms: those who only heard the audio description and those who saw the animated videos without the description. Students considered that the material helped in the inclusive and remote

\footnotetext{
${ }^{1}$ Mestranda no Programa de Pós-Graduação em Sistemática, Uso e Conservação da Biodiversidade (PPGSis) na Universidade Federal do Ceará (UFC). Graduada em Ciências Biológicas (UFC). E-mail: joannad.freitas@yahoo.com.br

${ }^{2}$ Graduada em Ciências Biológicas (UFC).E-mail: leticia-castrov@hotmail.com

${ }^{3}$ Professora do Departamento de Biologia, da Graduação em Ciências Biológicas e do Programa d e Pós-Graduação em Ensino de Ciências e Matemática e do PPGSis (UFC). Tutora do PET Biologia UFC. Doutora em Bioquímica (UFC). E-mail: erika.mota@ufc.br
} 
learning of immunology and the experience of participating in the learning of these students was of great value.

Keywords: Videos. Visual disability. Audio description. Bacteria. Remote teaching.

\section{Introdução}

Cerca de 3,4\% da população brasileira declara ter algum tipo de dificuldade visual e o Estatuto da Pessoa com Deficiência renovou as políticas de inclusão desses indivíduos na sociedade (INSTITUTO BRASILEIRO DE GEOGRAFIA E ESTATÍSTICA - IBGE, 2012; BRASIL, 2015). A Lei $n^{\circ} 13.409 / 2016$, por exemplo, refere-se às vagas para pessoas com deficiência no âmbito das Universidades Federais brasileiras, pressionando essas instituições a criar apoio acadêmico, estrutural, tecnológico e psicológico que permitam sua total integração à vida universitária (CHÁVEZ, QUIJIJE, 2018; GEDIEL, MOURÃO, MIRANDA, 2019). Tal medida gera novos desafios para os quais os professores devem encontrar soluções, de forma que todos os graduandos possam permanecer e completar essa fase de formação imprescindível para seu desenvolvimento profissional (DE VARGAS, 2006; MIRANDA, 2019; SEPTIMIO, MENDES, DA COSTA, 2019).

Baseando-se nesses dados, um projeto foi desenvolvido na disciplina de Estágio em Docência I de um Programa de Pós-Graduação, fazendo uso dos princípios do Desenho Universal para Aprendizagem (do inglês, Universal Design for Learning - UDL), que se baseia na adição prévia de acessibilidade ao plano de aula pautado nas necessidades dos estudantes, que podem receber as informações por meios visuais, auditórios, táteis ou multimídias de forma que todos aprendam (JOHNSTONE; AVAGYAN; MARUTYAN, 2018).

No âmbito do Ensino Superior, uma disciplina que poderia se beneficiar do uso deste tipo de metodologia é a imunologia. Nessa área, assim como outras da biologia, há conteúdos em que é necessário entender estruturas e funções na concepção microscópica, com alto nível de organização e complexidade (ZOGZA, 2016), sendo considerada uma disciplina conceitualmente difícil pelas suas nomenclaturas e terminologias (BELLEl et al., 2016). De acordo com Leal et al. (2015), diversificar a aula por meio de estratégias didáticas pode aumentar a compreensão por parte dos estudantes.

Além da sua dificuldade intrínseca, outros fatores podem afetar a devida compreensão dos conteúdos dessa disciplina, por exemplo, fatores externos, como a restrição de acesso às aulas presenciais imposta pela recente crise sanitária gerada pela pandemia de uma síndrome respiratória COVID-19 (Corona Virus Disease-2019) que assolou o mundo no ano de 2020 (PROMPETCHARA; KETLOY; PALAGA, 2020). Para tentar minimizar os prejuízos no âmbito educacional, o Ministério da Educação estabeleceu a portaria $n^{\circ} 343$, de 17 de março de 2020 (BRASIL, 2020) que dispõe sobre o uso de meios digitais para substituir as aulas presenciais durante a crise. Tudo isso foi considerado no 
momento de se pensar no projeto a ser desenvolvido junto aos alunos, atentando para a flexibilidade e a acessibilidade dos mesmos (CAMACHO et al., 2020).

O vídeo digital pode ser considerado um recurso educacional a ser usado como alternativa para superar essas dificuldades. Esse material possui grande potencial, principalmente na área das Ciências Biológicas, podendo ser uma ferramenta de suporte satisfatória e motivacional para tratar de conceitos e solução de problemas (SERAFIM; SOUSA, 2011). De acordo com Lima e Netto (2019), vídeos com menor duração e com estética animada dominam as plataformas online voltadas para educação, como forma de se atualizar ao público jovem, porém tais mídias que abordam imunologia são um dos mais escassos nesses ambientes.

Em relação à inclusão, a áudio-descrição pode ser facilmente adicionada aos vídeos didáticos. Esse artifício é considerado essencial, tanto no âmbito cultural como educacional, uma vez que pode garantir às pessoas com deficiência visual o mesmo acesso à informação que o disponibilizado às pessoas normovisuais, evitando a discriminação e auxiliando na sua educação profissional em áreas que fazem grande uso de conteúdo visual (LIMA; LIMA; GUEDES, 2009).

Nesse âmbito, o presente trabalho relata a confecção e uso de vídeos animados áudio-descritivos em aulas remotas (formato remoto emergencial) de imunologia, voltados, principalmente, mas não exclusivamente, ao aprendizado de forma inclusiva para portadores de deficiência visual. Esta foi a primeira experiência de formação docente da autora principal em desenvolver recursos didáticos e de participar do planejamento e execução de atividades em uma disciplina da graduação.

\section{Procedimentos metodológicos}

O material didático consistiu em três vídeos animados e curtos (duração < 20 min. aproximadamente) com narração. O primeiro abordou uma introdução sobre as características gerais da imunidade contra patógenos e os outros dois explicaram mais especificamente a imunidade contra bactérias intracelulares e extracelulares (Tabela 1). 
-Revista de Iniciação à Docência, v.6, n.2, 2021-

Publicação: dezembro, 2021 - ISSN 2525-4332

Tabela 1: Características e conteúdo dos vídeos confeccionados.

Título da série: “Animunologia: Imunidade contra patógenos”

\begin{tabular}{|c|c|c|c|}
\hline & Duração & Conteúdo & Minutagem \\
\hline Vídeo 1 - Introdução & $\begin{array}{l}13 \text { minutos; } \\
4 \\
\text { segundos. }\end{array}$ & $\begin{array}{l}\text { Apresentação } \\
1 \text { - "Os inimigos" - } \\
\text { Patógenos gerais } \\
2 \text { - Efetores - células da } \\
\text { imunidade inata e } \\
\text { adaptativa } \\
\text { 3- Coevolução } \\
4 \text { - Doença infecciosa } \\
5 \text { - Infecções latentes } \\
6 \text { - Doenças infecciosas } \\
\text { emergentes } \\
\text { Resumo e atividade de } \\
\text { reforço } \\
\text { Referências }\end{array}$ & $\begin{array}{l}00: 00-00: 43 \\
00: 44-02: 40 \\
02: 41-05: 28 \\
05: 29-07: 32 \\
07: 33-09: 27 \\
09: 28-10: 50 \\
10: 51-11: 49 \\
11: 50-12: 53 \\
12: 54-13: 04\end{array}$ \\
\hline $\begin{array}{l}\text { Vídeo } 2 \text { - Imunidade contra } \\
\text { bactérias extracelulares } \\
\text { Parte } 1\end{array}$ & $\begin{array}{l}15 \text { minutos; } \\
8 \\
\text { segundos }\end{array}$ & $\begin{array}{l}\text { Aviso } \\
\text { Apresentação } \\
\text { 1- Conhecendo o alvo - } \\
\text { estrutura da bactéria } \\
2 \text { - Portas de Entrada } \\
\text { 3- Adesão e Invasão } \\
\text { 4- Bactérias } \\
\text { extracelulares (Parte 1- } \\
\text { Imunidade Inata) } \\
\text { Aviso }\end{array}$ & $\begin{array}{l}00: 00-00: 03 \\
00: 04-00: 30 \\
00: 31-04: 32 \\
04: 33-06: 16 \\
06: 17-09: 23 \\
09: 24-14-58 \\
14: 59-15: 08\end{array}$ \\
\hline
\end{tabular}


Tabela 1: Características e conteúdo dos vídeos confeccionados. (continuação)

\begin{tabular}{|c|c|c|c|}
\hline $\begin{array}{l}\text { Vídeo } 3 \text { - Imunidade contra } \\
\text { bactérias extracelulares e } \\
\text { intracelulares } \\
\text { Parte } 2\end{array}$ & $\begin{array}{l}21 \text { minutos; } \\
26 \\
\text { segundos }\end{array}$ & $\begin{array}{l}\text { Aviso } \\
4 \text { - Bactérias } \\
\text { extracelulares (Parte } 2 \text { - } \\
\text { Imunidade adaptativa) } \\
5 \text { - Efeitos lesivos } \\
6 \text { - Mecanismos de } \\
\text { escape das (bactérias) } \\
\text { extracelulares } \\
7 \text { - Bactérias } \\
\text { intracelulares } \\
8 \text { - Mecanismos de } \\
\text { escape das (bactérias) } \\
\text { intracelulares } \\
\text { Resumo e atividade de } \\
\text { reforço } \\
\text { Referências }\end{array}$ & $\begin{array}{l}10: 34-17: 55 \\
17: 56-19: 49 \\
19: 50-20: 49 \\
20: 50-21: 26\end{array}$ \\
\hline
\end{tabular}

Fonte: Autoria Própria

Foi realizado, primeiramente, um levantamento bibliográfico acerca do mecanismo de defesa do corpo contra infecções, principalmente por bactérias, bem como sobre educação inclusiva e deficiência visual. Essa pesquisa auxiliou na escrita de uma sequência didática (ROCHA, MOTA, 2021) e dos roteiros da narração da animação e do texto para a áudio-descrição. Neste último caso, a confecção foi realizada de acordo com Lima (2011), atentando-se para a concisão (mínimo de palavras em curto espaço de tempo, objetivo e direto), clareza, exatidão, especificidade (usar termos que expressem a ideia mais precisa) e vividez.

Tomando como base o roteiro escrito, foram criadas ilustrações no programa Adobe Illustrator $\mathrm{CS}_{3}$ (Adobe ${ }^{\circledR}$ ), que consistiram em desenhos com cores vivas no estilo cartoon. Esse programa não é gratuito, mas existem outros similares que podem ser usados, como o Inkscape, o que facilita a reprodutibilidade da metodologia por parte de outros docentes. O programa PowerPoint (Microsoft ${ }^{\circledR}$ ) foi utilizado para a criação das animações em 2D, através da aplicação de ações de movimento nas ilustrações com os botões programáveis embutidos no próprio programa (O’DAY, 2006). Esse software foi escolhido por ser um substituto mais simples e fácil de utilizar do que programas específicos de animação. Assim como o Illustrator, esse programa pode não ser acessível a todos, mas suas ferramentas podem ser encontradas em similares gratuitos, como o LibreOffice. Algumas das ilustrações foram transformadas em arquivos tipo GIF utilizando o Adobe Photoshop CS6 (Adobe $\left.{ }^{\circledR}\right)$, para melhorar o efeito do movimento antes de importá-lo para 
o PowerPoint. Esse artifício pode ser realizado no programa gratuito Krita.

A gravação de áudio-descrição foi feita seguindo as diretrizes propostas por Lima, Guedes e Guedes (2009), como evitar sobreposição da áudio-descrição a outras narrações ou efeitos sonoros importantes, não utilizar expressões ambíguas e linguagem rebuscada ou subjetiva para que não perturbe a compreensão e interpretação pessoal de quem escuta. Como os vídeos foram narrados e áudio-descritos pela mesma pessoa, a áudiodescrição passou por um processo de modulação com o auxílio de um programa de edição para ficar mais grave e distinta da narração. Além da áudio-descrição, foram adicionadas legendas aos vídeos para ampliar o público beneficiado pelo material. A gravação da tela do Powerpoint e do áudio da narração foram feitos pelos programas oCam e Audacity, respectivamente. Os efeitos sonoros foram adquiridos em sites que disponibilizam soundtracks gratuitos, como o Freesound. A edição do vídeo foi feita através do programa Kdenlive. Os vídeos confeccionados foram colocados em um site de armazenamento (nuvem) do Google Drive. Após o upload, foi gerado um link para compartilhamento que foi distribuído aos alunos para aplicação do material (vide Material Suplementar).

Antes da aplicação foi requisitado aos alunos que respondessem a um breve questionário, mediante formulário do Google Docs, para averiguar o perfil da turma e o conhecimento prévio acerca da imunidade contra patógenos, especificamente sobre bactérias intracelulares e extracelulares. Após a aplicação, outro formulário foi passado para avaliação do material, contendo tanto questões subjetivas quanto objetivas e baseadas na escala de Likert com gradação de cinco pontos (LIKERT, 1932).

O material foi aplicado na semana do dia 28 de setembro de 2020, mediante plataforma do Ambiente Virtual de Aprendizagem da Universidade onde foi aplicada. Os alunos foram divididos de forma aleatória, onde parte da turma recebeu um link com a animação e a outra parte recebeu um link para um arquivo somente com o áudio, para simular a perda de visão total. Um período de uma semana foi dado para que os alunos pudessem avaliar o conteúdo dos vídeos, mediante um segundo formulário, levando-se em consideração a situação da pandemia pela COVID-19, em que muitos alunos estavam em situação desfavorável de acesso à internet, além das atribulações emocionais que afloram nessas situações (ARRUDA, 2020). Após esse período, todos os alunos tiveram acesso à forma completa dos vídeos.

Foi apresentado, junto ao formulário online, um termo de consentimento livre e esclarecido (TCLE) para cada um dos participantes, a fim de que estes pudessem estar cientes de sua colaboração para o desenvolvimento da pesquisa. A aplicação do material foi feita somente após aprovação e consentimento dos participantes, registrados por meio de TCLE. Essa pesquisa segue as orientações da Resolução n. 510, de 7 de abril de 2016, que dispõe sobre as normas aplicáveis a pesquisas em Ciências Humanas e Sociais. Não foi submetida para apreciação do Comitê, uma vez que em seu artigo $1^{\circ}$, parágrafo 
único, estabelece:

Não serão registradas nem avaliadas pelo sistema CEP/CONEP: [...] VII -pesquisa que objetiva o aprofundamento teórico de situações que emergem espontânea e contingencialmente na prática profissional, desde que não revelem dados que possam identificar o sujeito; VIII - atividade realizada com o intuito exclusivamente de educação, ensino ou treinamento sem finalidade de pesquisa científica, de alunos de graduação, de curso técnico, ou de profissionais em especialização. (CONSELHO NACIONAL DE SAÚDE - CNS, 2016, p.2)

\section{Resultados e Discussões}

O presente trabalho consistiu na utilização de vídeos com ilustrações animadas e áudio-descrição em ensino remoto e inclusivo de imunologia em uma turma de graduação e fez parte das atividades de uma disciplina de estágio em docência no ensino superior. Essa foi também uma demanda para auxiliar na adaptação da disciplina no formato remoto, pois esta já é considerada difícil e complexa e no ambiente virtual as dificuldades de adaptação dos materiais tornam-se ainda maiores. Em relação à inclusão, Silva (2020, p. 59) ressalta que as dificuldades se "acentuam quando faltam recursos acessíveis para o ensino de disciplinas que possuem em seu conteúdo uma maior quantidade de informações visuais, como a Imunologia".

Foi muito interessante conversar com os alunos durante as aulas e notar que ficaram interessados e com grandes expectativas quando foram informados da abordagem didática. De Souza (2014) relata que as ilustrações no âmbito da biologia são ferramentas de ensino apropriadas e lúdicas, que auxiliam na assimilação de conceitos, enfatizando o pensamento criativo dos alunos. Ainda nesse relato, Souza (2014) informa que o uso de vídeo possibilita uma apresentação dinâmica, despertando o interesse do aluno, como foi observado.

Inicialmente, foi requisitado aos alunos que preenchessem um formulário com questões sobre o perfil dos estudantes e seu conhecimento prévio acerca do tema. Isso foi necessário, já que as aulas estavam sendo remotas e não se tinha o contato diário com os alunos para conhecê-los melhor. Com relação ao perfil dos participantes, 92,9\% possuíam dispositivos com bom acesso à internet para a visualização de vídeos, enquanto $7,1 \%$ alegaram possuir, mas com acesso ruim. Tal resultado é similar ao de Passarelli e Angeluchi (2018), em que 94,23\% dos estudantes entrevistados declararam possuir dispositivos smartphones e geralmente buscar outras formas de acesso à internet que não dependam somente do próprio pacote de dados.

Com relação à dificuldade visual, a maioria dos alunos respondeu possuir tanto miopia quanto astigmatismo e alguns afirmaram possuir apenas uma das duas condições (Figura 1). 
Figura 1: Caracterização da dificuldade visual dos estudantes

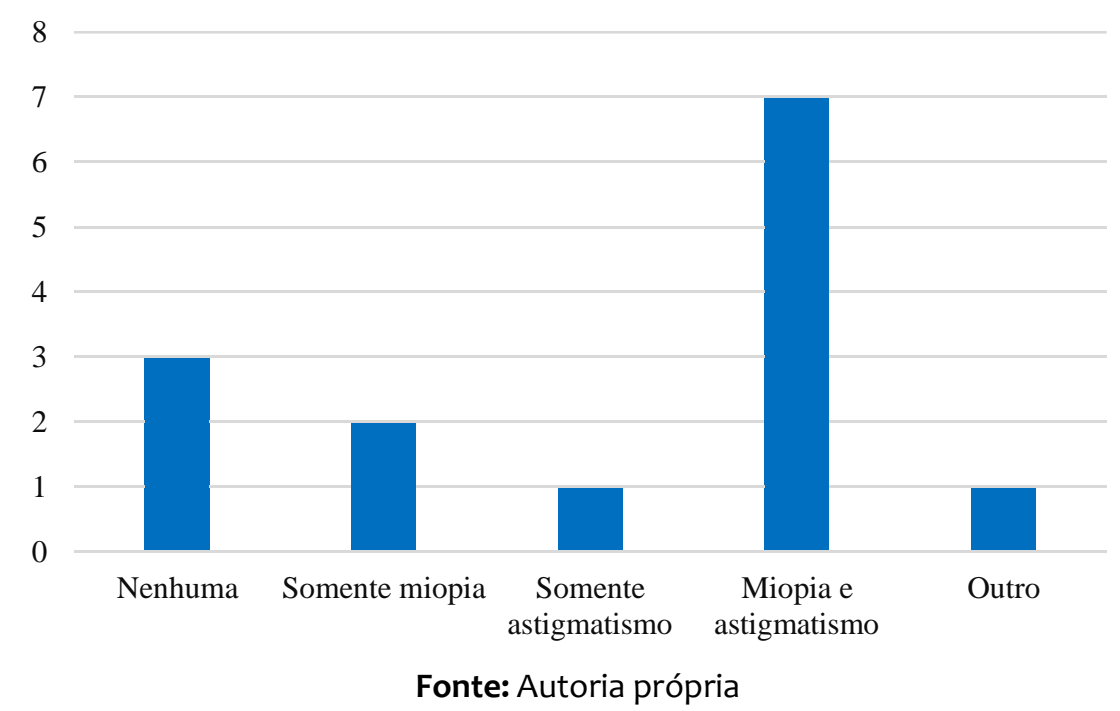

Um dos alunos respondeu ter também sensibilidade à luminosidade e que ficar muito tempo na frente de uma tela lhe causava dor de cabeça ou enxaqueca. Nenhum dos estudantes declarou possuir deficiência visual, ou seja, um comprometimento parcial (de 40 a 60\%) ou total da visão (AMPUDIA, 2011).

De acordo com Silva et al. (2015), há uma correlação positiva entre os problemas visuais relatados, inclusive as dores de cabeça, com o aumento da utilização de dispositivos digitais, provavelmente por conta da exposição do olho à luz azul-violeta. No entanto, devido à pandemia, o uso desse tipo de recurso se tornou mais frequente e essencial para as aulas remotas. A decisão por vídeos de duração curta foi uma decisão acertada, pois permitiu a visualização breve do estudante ao dispositivo, auxiliando nessa questão.

Com relação ao material inclusivo com áudio-descrição, 57,1\% dos estudantes responderam já terem tido contato com esse tipo de recurso, enquanto $43 \%$ nunca tiveram ou não lembram de terem ouvido antes. Esse dado é estimulante e pode sugerir que materiais para inclusão estão cada vez mais presentes na sociedade, já que mais da metade dos alunos participantes, apesar de não necessitarem, já se depararam com esse artifício.

As últimas questões incluídas no formulário prévio foram relacionadas à disciplina de imunologia. Para tanto, foi perguntado aos alunos qual o grau de dificuldade que eles consideravam a imunologia, utilizando-se uma escala de tipo Likert de cinco pontos, em que 1 significa "muito difícil" e 5 "muito fácil” (Figura 2). $50 \%$ dos alunos consideraram a disciplina mediana, ou seja, não é difícil, mas também não é fácil. 35,7\% consideram difícil e apenas $14,3 \%$ a consideraram fácil. 
Figura 2: Percepção dos estudantes sobre a disciplina de imunologia

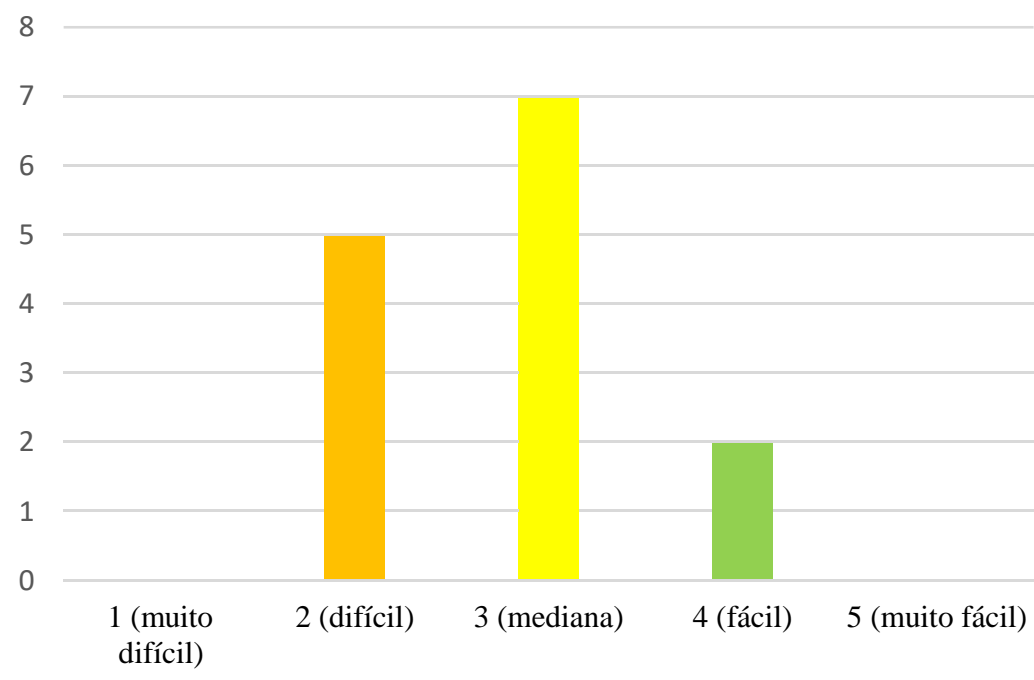

Fonte: Autoria própria

Foi pedido que, caso quisessem, justificassem sua resposta e a maioria dos estudantes afirmou que a disciplina em si não é difícil, mas a quantidade de conteúdo, a presença de muitos termos e siglas, diferentes rotas metabólicas e muitos processos e "detalhes moleculares" tornam a disciplina complexa. Os estudantes, que consideraram a imunologia como difícil, relacionaram essa dificuldade com a falta de contato prévio com o assunto no ensino médio e descreveram que as "ligações do conteúdo" tornam a disciplina confusa. Dentre os motivos para considerarem fácil constou-se "gostar da área" e possuir características com outras disciplinas já estudadas, como Bioquímica. Interessantemente, ao serem perguntados se gostavam da disciplina, a maioria respondeu que sim (42,9\% que "gostam" e 14,3\% que "gostam muito"), contra 35,7\% que eram neutros e 7,1\% que não gostavam (Figura 3).

Figura 3: Apreciação dos estudantes pela disciplina de Imunologia

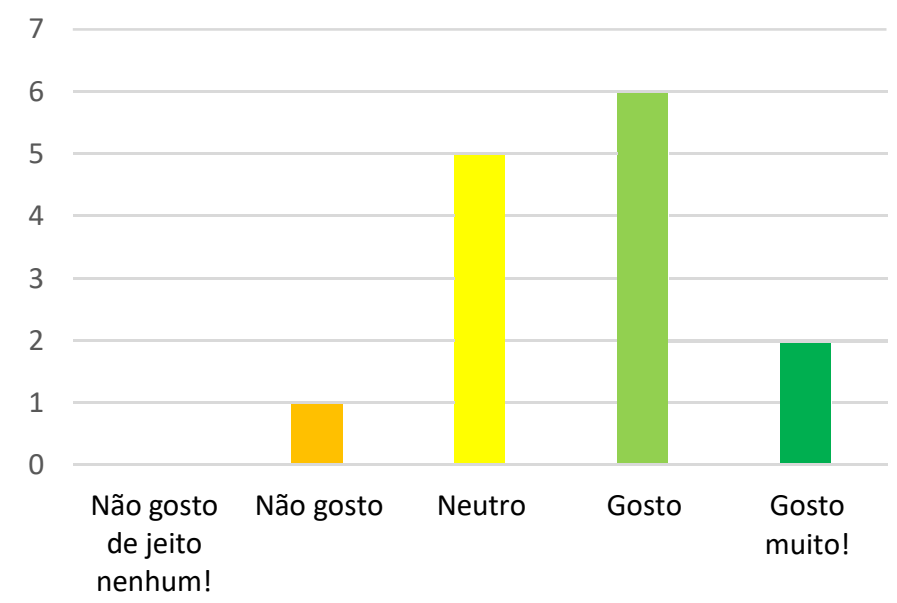

Fonte: Autoria própria

Aparentemente, gostar da disciplina não seria um fator forte o suficiente para 


\section{-Revista de Iniciação à Docência, v.6, n.2, 2021- \\ Publicação: dezembro, 2021 - ISSN 2525-4332}

considerá-la mais fácil de estudar, visto que muitas das justificativas parecem indicar que, apesar de interessante, a complexidade e a extensão do assunto são os principais empecilhos. Percebeu-se que diversos fatores podem influenciar no ensino e aprendizagem, para Silva, Falcão e Dantas (2021, p. 87), "o uso adequado de estratégias de estudo e aprendizagem tem sido relacionado com o desempenho acadêmico e a motivação dos estudantes do ensino superior". Esses mesmos autores também relatam que a forma como os alunos estudam o conteúdo programático pode tornar-se um fator limitante na fixação, o que acaba por interferir no processo de ensino e aprendizagem. Em relação à inclusão, Silva (2020) considera que a falta de recursos adaptados às especificidades do aluno com deficiência visual pode resultar na falta de interesse e desmotivação profissional.

Para avaliação do material, 57,1\% dos estudantes participantes receberam somente a áudio-descrição, como forma de simular a deficiência visual total, e 42,9\% receberam o vídeo com a animação para avaliar quanto ao uso dos vídeos na disciplina (Figuras 4 e 5) e quanto à qualidade dos vídeos elaborados (Figuras 6 e 7).

Figura 4: Percepção do estudante quanto à utilidade dos vídeos no ensino inclusivo

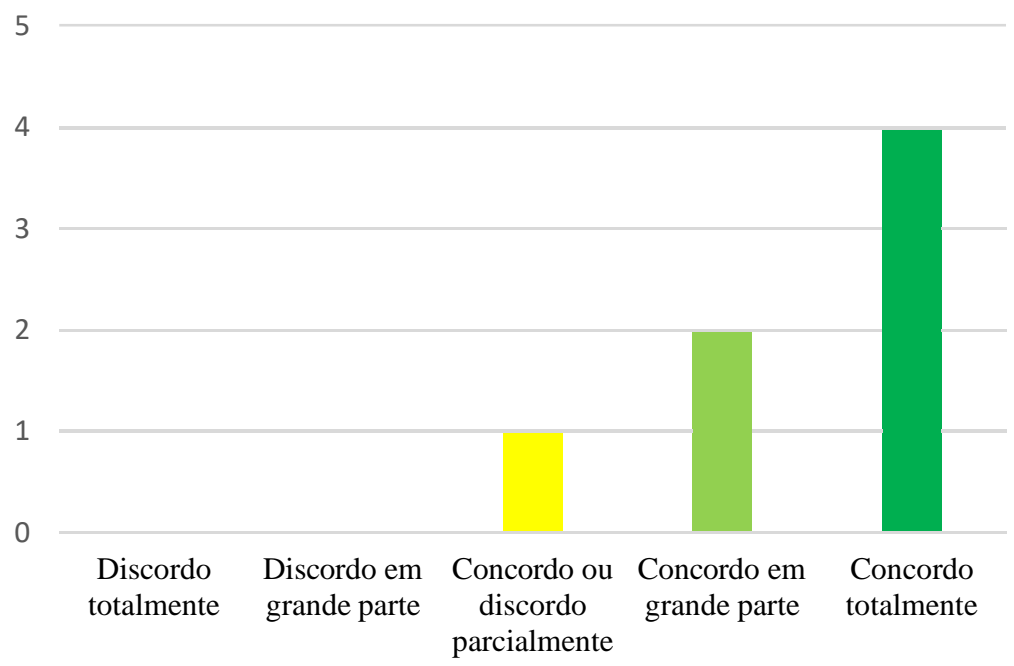

Fonte: Autoria própria

Figura 5: Percepção do estudante quanto a capacidade dos vídeos de facilitar o estudo de forma divertida

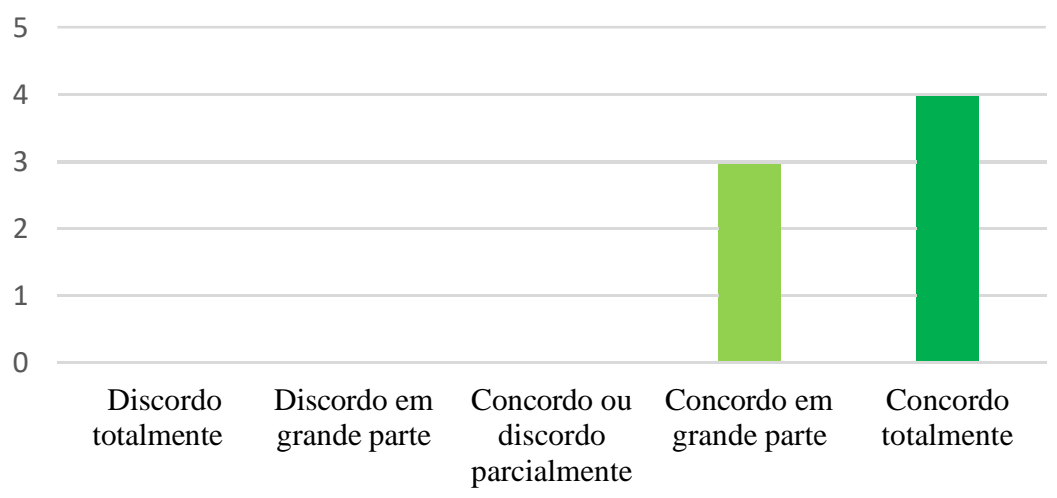

Fonte: Autoria própria 
Figura 6: Parâmetros visuais dos vídeos avaliados pelos estudantes

Imagem e Edição

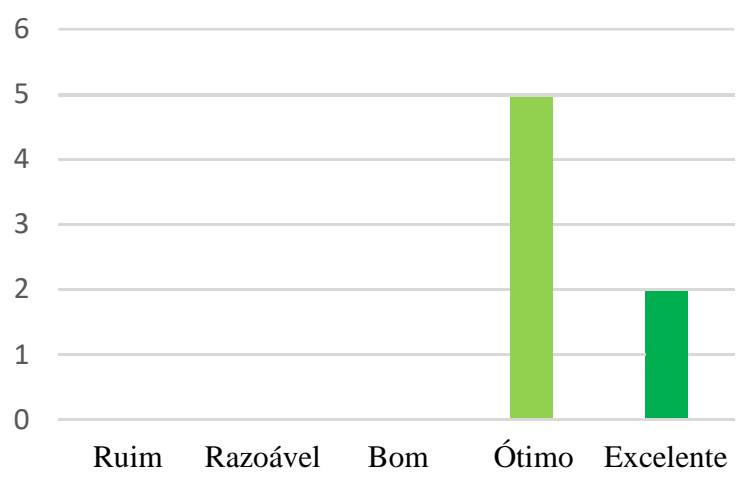

Ilustrações ou vividez

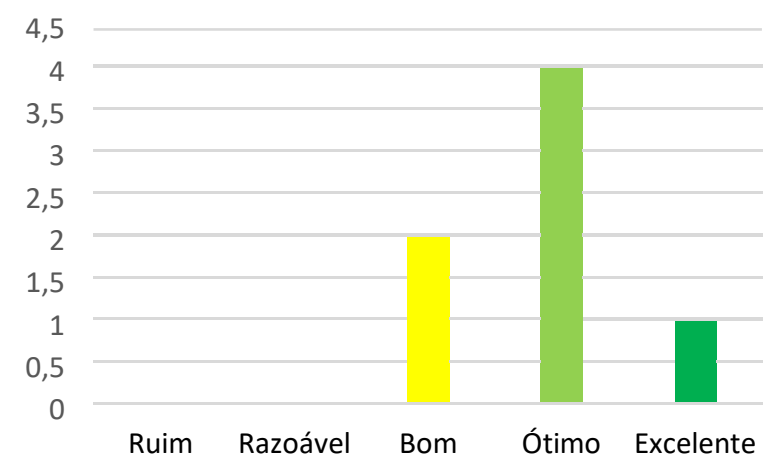

Fonte: Autoria própria

Figura 7: Demais parâmetros dos vídeos avaliados pelos estudantes
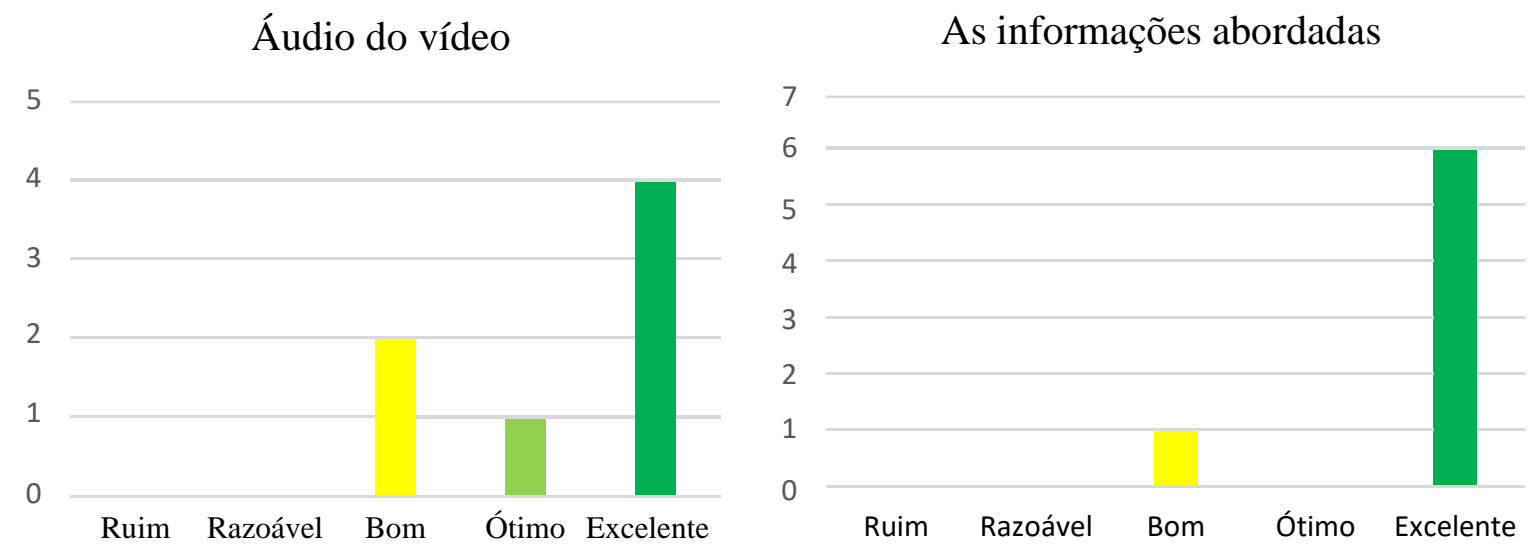

Fonte: Autoria própria

A escolha de se utilizar animações em formato cartoon (Figura 8) foi feita, justamente, com objetivo de tentar criar um vínculo afetivo com o assunto, de modo a facilitar seu estudo, já que muitos atribuíram a dificuldade a uma falta de interesse e afinidade pela matéria. Pelas respostas recebidas, a afetividade com a disciplina parece ter sido instigada com sucesso. 
Figura 8: Exemplo de um frame (quadro) do vídeo confeccionado, onde se lê “Mecanismos de escape das [bactérias] extracelulares" mostrando as ilustrações presentes no vídeo, em formato cartoon

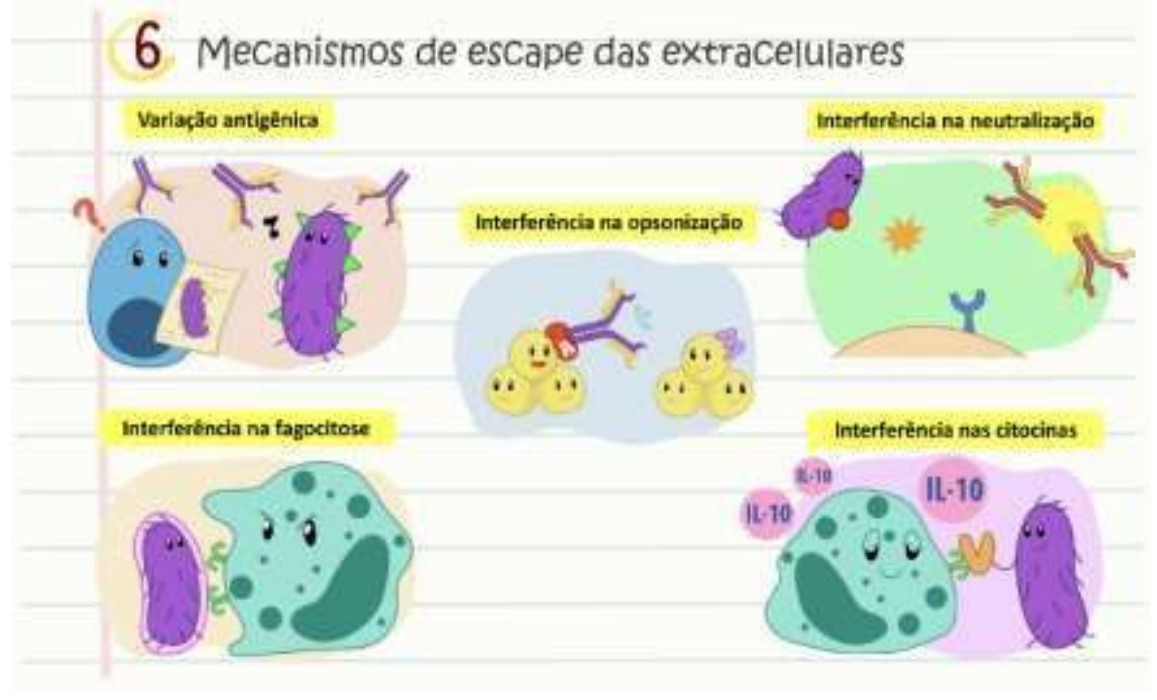

Fonte: Autoria própria

Além da escala, um espaço opcional no formulário foi destinado para sugestões, críticas e elogios quanto ao uso dos vídeos na disciplina. Um dos estudantes relatou: "Os vídeos ficaram excelentes! Parabéns pela iniciativa e a preocupação com a acessibilidade", demonstrando a boa aceitação do material didático.

Quanto à qualidade do vídeo em si, muitas sugestões e críticas construtivas foram recebidas. Com relação ao tempo de vídeo, alguns alunos acharam razoável, sugeriram que fosse menor para "alcançar os alunos" e que "20 minutos se tornam cansativos no caso da áudio-descrição", mas compreendiam que, "como o conteúdo em si é extenso", não teriam "certeza de que seria benéfico" se fosse mais breve, mesmo os vídeos já sendo mais curtos do que aulas convencionais (duração de $\pm 13, \pm 15$ e \pm 20 minutos, respectivamente). No entanto, após analisar as respostas dos alunos, observou-se que estas vão ao encontro de estudos que sugerem que quanto mais curtos os vídeos, maior o engajamento dos estudantes, sendo o tempo ideal sugerido o de seis a nove minutos (GUO; KIM; RUBIN, 2014). No entanto, pode se justificar que o tempo do vídeo produzido ficou um pouco maior que o ideal sugerido porque optou-se por adicionar na áudiodescrição detalhes das ilustrações desenvolvidas a fim de tentar passar a mesma experiência que os normovisuais receberiam (incluindo descrição de cores e movimentos). Essa decisão foi feita com intuito de se aumentar a vividez, mas acabou pecando pela falta de concisão. De acordo com Seemann (2019), as frases longas nas descrições é um dos erros mais comuns em roteiros de áudio-descrição realizados por iniciantes, seguido do uso desnecessário de pronomes ou uso errôneo de artigos. Esses dois últimos fatores não foram indicados pelos estudantes, mas a áudio-descrição dos 
vídeos necessitaria passar por novas revisões para se certificar de que esses pontos não foram prejudicados.

Um dos estudantes fez uma observação pertinente quanto à descrição das cores, que "para a áudio-descrição, poderia não ser adequado". No entanto, como o mesmo aluno considerou, há deficiências visuais totais e parciais que precisam ser levadas em consideração. De acordo com Alves, Teles e Pereira (2011), a descrição das cores é recomendada, pois a maioria dos deficientes retém memória de cores de quando possuía visão útil e, mesmo aqueles em condição congênita conseguem assimilar significados através das cores, como vermelho ser de paixão ou perigo.

Quanto à vividez, ou seja, a capacidade de imaginar uma situação através de áudio, um dos alunos comentou que tem "bastante dificuldade em imaginar situações através de áudio, mas nesse caso a descrição foi ótima”, o que pode indicar que, possivelmente, um aluno portador de deficiência também se beneficie desse recurso.

Com relação à qualidade de som, de forma geral, a narração agradou e a diferenciação da voz, alterada pelo programa, "ajuda a manter a concentração e entender melhor a explicação". No entanto, foi considerada um pouco lenta e algumas vezes tiveram dificuldade de "entender uma palavra ou outra, mas nada que voltar um pouco e ouvir de novo não resolvesse". Em algumas partes do vídeo, "a música de fundo ficava alta ou tinha batidas forte, o que acabou atrapalhando" e foi sugerida a utilização de músicas com instrumentos de sopro ou corda, pois são mais suaves. A inclusão da música deveria "aguçar a percepção do espectador em torno do assunto que está sendo tratado" (LIMA; NETTO, 2019, p.185), no entanto, da maneira como foi incluída acabou prejudicando o entendimento de alguns alunos.

Como alternativa, efeitos sonoros poderiam ser utilizados ao invés da música. McElligott e Van Leeuwen (2004) obtiveram sucesso no design de sons para crianças com deficiência visual, auxiliando na identificação de espaço, distâncias e movimentos. Da mesma forma, aos processos imunológicos poderiam ser atribuídos sons especiais para melhor entendimento e sucesso da abordagem inclusiva, melhorando a vividez dos vídeos sem prejudicar a compreensão do estudante com narrações prolongadas.

Como o projeto fez parte de uma avaliação de uma disciplina de Pós-Graduação, os resultados aqui descritos, por mais que avaliem a aplicabilidade do material didático, possui intenção de relatar a experiência vivida na sala de aula remota e na aplicação desse projeto pela estudante de Mestrado. Dessa forma, também se perguntou aos alunos quanto à atuação da iniciante em docência durante a disciplina (Figura 9). 
Figura 9: Percepção dos estudantes quanto à atuação da iniciante em docência

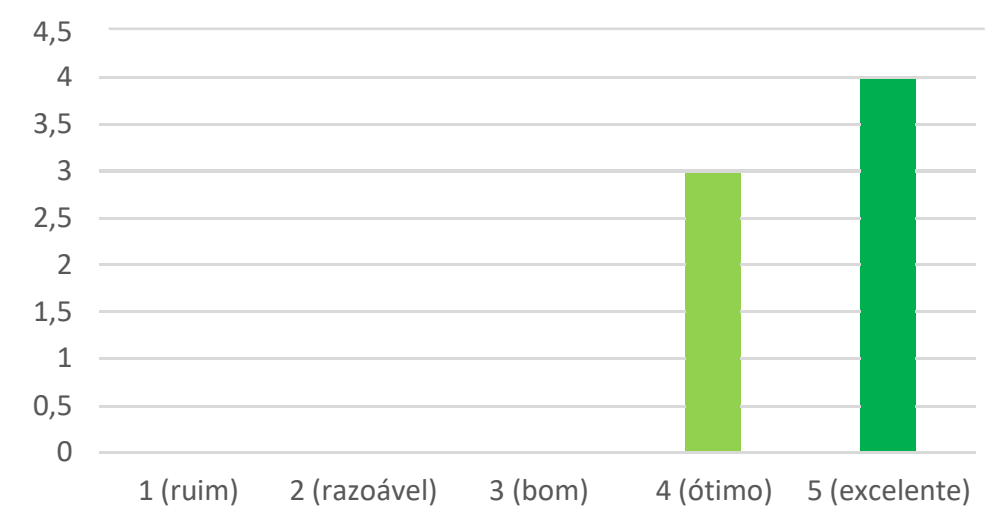

Fonte: Autoria própria

O resultado foi recebido com grande alegria e com sentimento de dever cumprido. Acredita-se que esse sentimento seja o mesmo, independente de quantos anos de carreira magistral o docente possua. $\mathrm{E}$, realmente, parece haver uma correlação positiva entre satisfação intrínseca do trabalho de docente com o tempo na profissão e com a quantidade de alunos que o docente leciona (TREVIZANI; MARIN, 2020).

Apesar de se tratar de uma turma pequena, as respostas obtidas foram relevantes para agregar conhecimento na área, contribuir para formação docente, desde à maneira de se portar em uma sala de aula, mesmo que virtual, até despertar no estudante de estágio em docência o interesse quanto à potencialidade das metodologias ativas e inclusivas. No entanto, alguns obstáculos tiveram que ser enfrentados durante a disciplina, e alguns estão relacionados ao momento de pandemia vivenciado, restrições de acesso à sala de aula presencial, dificuldade de comunicação com os discentes, que pode ter refletido na participação tanto na aula em si quanto na avaliação do material didático pela turma. Bem como, o pequeno número amostral, já que dos 30 estudantes matriculados na turma, 14 concordaram em participar do questionário prévio e apenas 7 participaram da avaliação do material.

Pela observação durante a disciplina, uma série de fatores contribuíram para isso. Primeiro, como os próprios alunos relataram, a aplicação do material didático coincidiu com uma grande carga de conteúdo decorrente do fim do semestre e avaliações finais de muitas disciplinas. Além disso, os estudantes estavam passando por um período de habituação ao ensino remoto, uma das medidas adotadas para conter o avanço da pandemia por coronavírus. Nesse período atípico, o contato do professor com o aluno para retirar as dúvidas de forma mais individualizada foi dificultado (OLIVEIRA; SOUZA, 2020), portanto os alunos estavam se acostumando ao ambiente virtual, a terem maior responsabilidade e autonomia, construindo seus próprios horários de estudo e "exercendo um papel mais ativo do que o fazia quando frequentava às aulas nos horários 
previamente determinados e recebia o conteúdo passivamente." (SPALDING et al., 2020, p.19).

Outro ponto a ser salientado foram os problemas de conexão que ocorreram durante a disciplina. Em alguns momentos, o Ambiente Virtual de Aprendizagem, onde os alunos tinham acesso às aulas e atividades como os vídeos animados, não suportava a quantidade de usuários simultâneos e chegou a ficar fora do ar. Além disso, "é preciso ter consciência das condições de acesso dos estudantes às tecnologias disponíveis e, principalmente à internet, para continuidade dos seus estudos de forma remota" (SANTOS JUNIOR; SILVA MONTEIRO, 2020, p.13), assim não se pode garantir que todos os estudantes tiveram acesso aos formulários no período de avaliação estipulado a eles ou que conseguiram assistir a todos os vídeos, mas foi garantido a eles acesso ao site de armazenamento para que conseguissem desfrutar desse material mesmo com o fim da disciplina. Não menos importante, a pandemia pode provocar efeitos deletérios na saúde mental dos estudantes universitários (MAIA; DIAS, 2020). Realmente, durante a disciplina, houve relatos de estudantes que estavam passando por crises de depressão e ansiedade e não estavam conseguindo acompanhar as aulas ou realizar as atividades no período estipulado. Para esses casos, houve uma flexibilização da entrega das demais atividades da disciplina.

Mesmo com todos esses obstáculos, a comparação das respostas ao questionário antes do início da atividade e depois da aplicação dos vídeos animados indicou que os alunos tiveram um aprendizado satisfatório. Destaca-se que foi requisitado dos alunos que não pesquisassem a resposta correta nesses questionários, visto que o intuito não era atribuir nota, mas para auxiliar na pesquisa e averiguar o conhecimento prévio sobre o assunto. Após a apreciação dos vídeos, os alunos conseguiram responder as questões que previamente deixaram incompletas ou responderam não saber o conteúdo.

\section{Considerações finais}

A experiência de formação docente possibilitou o olhar das autoras para o ensino inclusivo e o interesse em se buscar as melhores formas de se passar o conhecimento acerca do conteúdo de imunologia de forma inclusiva e atendendo às demandas e adaptações ao ensino remoto emergencial. Expressar as reações e interações do organismos de forma lúdica para aqueles que não contam com o sentido da visão foi a principal dificuldade encontrada e, tal dificuldade, pode ser sentida pelos alunos que simularam a perda de visão ao escutar somente a áudio-descrição.

Apesar das limitações, observou-se que os vídeos foram bem aceitos pela turma e que, de acordo com eles, esse material pode auxiliar no aprendizado. As sugestões acerca da utilidade dos vídeos para aulas de imunologia inclusivas e remotas foram pertinentes, destacando-se a mudança da música de fundo e a utilização de narração mais dinâmica e menos lenta. Nesse quesito, acredita-se que a áudio-descrição ainda pode ser melhorada 
e os vídeos confeccionados podem ser futuramente aplicados a alunos que realmente necessitem desse recurso, podendo ser uma meta a ser estipulada para os próximos Estágios em docência.

Destaca-se ainda, como relato de experiência na docência, o primeiro contato com uma turma de estudantes gerou grande aprendizado e foi desafiador por ter ocorrido em momento de restrições de isolamento impostas pela pandemia e suas consequências. Esta experiência demonstrou o quanto os docentes são também eternos estudantes, dedicando-se a aprenderem novas maneiras de ensinar para além das adversidades e ao alcance de todos. Portanto, espera-se que esse relato possa inspirar outros estudantes iniciantes em docência e docentes em formação contínua a pensar em novos materiais e novas abordagens que facilitem a acessibilidade no ensino.

\section{Material suplementar}

Os vídeos confeccionados (somente com a áudio-descrição sem imagens, sem a áudio-descrição com imagens e completo com as duas formas), bem como o questionário/formulário aplicado, constam no seguinte link do Google Drive: https://drive.google.com/drive/folders/1inqdpQ7p5mtv8DoR2ysbFEy6tn1-

V3jd?usp=sharing

\section{Agradecimentos}

Os autores agradecem à CAPES (Coordenação de Aperfeiçoamento de Pessoal de Nível Superior) pelo apoio financeiro da bolsa de Pós-Graduação e ao grupo de alunos que participaram da avaliação do material confeccionado.

\section{Referências}

ALVES, Soraya Ferreira; TELES, Veryanne Couto; PEREIRA, Tomás Verdi. Propostas para um modelo brasileiro de audiodescrição para deficientes visuais. Tradução \&

Comunicação, v. 22, 2011.

AMPUDIA, Ricardo. O que é Deficiência Visual. Revista Nova Escola, 2011. Disponível em: https://novaescola.org.br/conteudo/270/deficiencia-visual-inclusao. Acesso em: 12 mar. 2021.

ARRUDA, Eucidio Pimenta. Educação remota emergencial: elementos para políticas públicas na educação brasileira em tempos de Covid-19. EmRede-Revista de Educação a Distância, v. 7, n. 1, p. 257-275, 2020.

BELLEI, Maria et al. A cost-effective approach to producing animated infographics for immunology teaching. Journal of microbiology \& biology education, v. 17, n. 3, p. 477, 2016. 
-Revista de Iniciação à Docência, v.6, n.2, 2021-

Publicação: dezembro, 2021 - ISSN 2525-4332

BRASIL. Lei n. 13.146, de 6 de jul. de 2015. Lei Brasileira de Inclusão da Pessoa com Deficiência. 2015. Disponível em: http://www.planalto.gov.br/ccivil_03/_Ato20152018/2015/Lei/L13146.htm. Acesso em: 24 mar. 2021.

BRASIL. Portaria $\mathbf{N}^{\circ} 343$ de 17 de março de 2020. Disponível em:

https://www.in.gov.br/en/web/dou/-/portaria-n-343-de-17-de-marco-de-2020-248564376. Acesso em: 22 ago. 2020

CAMACHO, A. C. L. F. et al. Tutoring in distance education in times of COVID-19: relevant guidelines. Research, Society and Development, v. 9, n. 5, p. e30953151, 2020.

CHÁVEZ, Sandra Auxiliadora Romero; QUIJIJE, Karen Katherine Bowen. A Challenge for Teachers of Inclusive Higher Education. International research journal of management, IT and social sciences, v. 5, n. 2, p. 129-135, 2018.

CONSELHO NACIONAL DE SAÚDE - CNS. Resolução N 510, de 07 de Abril de 2016.

Disponível em: http://conselho.saude.gov.br/resolucoes/2016/Reso510.pdf Acesso em: 30 ago. 2020.

GEDIEL, Ana Luísa Borba; MOURÃO, Victor Luiz Alves; MIRANDA, Isabela Martins. A Inclusão e suas práticas aspectos socioantropológicos da produção de materiais pedagógicos inclusivos para Surdos. Anuário antropológico, n. I, p. 135-158, 2019.

GUO, Philip J.; KIM, Juho; RUBIN, Rob. How video production affects student engagement: An empirical study of MOOC videos. In: Proceedings of the first ACM conference on Learning@ scale conference.p.41-50, 2014.

INSTITUTO BRASILEIRO DE GEOGRAFIA E ESTATÍSTICA - IBGE. Censo Demográfico 2010: características gerais da população, religião e pessoas com deficiência. Rio de Janeiro: IBGE, 2012. Disponível em:

https://biblioteca.ibge.gov.br/visualizacao/periodicos/94/cd_2010_religiao_deficiencia.pdf Acesso em: mar. 2021.

JOHNSTONE, Christopher; AVAGYAN, A.; MARUTYAN, M. Chapter 2: Universal Design for Learning. In: Tichá, R., Abery, B., Johnstone, C., Poghosyan, A., \& Hunt, P. (Eds.). Inclusive Education Strategies: A Textbook. Minneapolis, MN, USA: University of Minnesota; Yerevan, Armenia: UNICEF Armenia \& Armenian State Pedagogical University, 2018.

LEAL, Cristianne Antunes et al. O que dizem os estudantes sobre a linguagem científica da Biologia. In: IV Simpósio em Ensino de Ciências e Meio Ambiente do Rio de Janeiro.

UnifOA. Revista Práxis. Edição especial. Ano VII, p. 425, 2015.

LIKERT, Rensis. A technique for the measurement of attitudes. Archives of psychology, 1932.

LIMA, Francisco J.; LIMA, Rosângela AF; GUEDES, Lívia C. Em Defesa da Áudio-descrição: contribuições da Convenção sobre os Direitos da Pessoa com Deficiência. Revista Brasileira de Tradução Visual, v. 1, n. 1, p. 1-23, 2009.

LIMA, Francisco José. Introdução aos estudos do roteiro para áudio-descrição: sugestões para a construção de um script anotado. Revista brasileira de tradução visual, v. 7, n. 8, 2011.

LIMA, Talitha Tiyomi; NETTO, Martha Cristina Motta Godinho. Vídeos Curtos Animados: Aspectos a serem considerados no ensino de biologia. Comunicações, v. 26, n. 2, p. 179- 
195, 2019.

MAIA, Berta Rodrigues, DIAS, Paulo César. Ansiedade, depressão e estresse em estudantes universitários: o impacto da COVID-19. Estudos de Psicologia (Campinas), 37, e200067, 2020.

MCELLIGOTT, Joanne; VAN LEEUWEN, Lieselotte. Designing sound tools and toys for blind and visually impaired children. In: Proceedings of the 2004 conference on Interaction design and children: building a community. p. 65-72, 2004.

MIRANDA, Fabiana Darc. Aspectos Históricos da educação Inclusiva no Brasil. Pesquisa e Prática em Educação Inclusiva, v. 2, n. 3, p. 11-23, 2019.

O'DAY, Danton H. Animated cell biology: A quick and easy method for making effective, high-quality teaching animations. CBE-Life Sciences Education, v. 5, n. 3, p. 255-263, 2006.

OLIVEIRA, Hudson do Vale; DE SOUZA, Francimeire Sales. Do conteúdo programático ao sistema de avaliação: reflexões educacionais em tempos de pandemia (COVID-

19). Boletim de Conjuntura (BOCA), v. 2, n. 5, p. 15-24, 2020.

PASSARELLI, Brasilina; ANGELUCI, Alan César Belo. Conectividade contínua e acesso móvel à informação digital: jovens brasileiros em perspectiva. Informação \& Sociedade, v. 28, n. 2, 2018.

PROMPETCHARA, Eakachai; KETLOY, Chutitorn; PALAGA, Tanapat. Immune responses in COVID-19 and potential vaccines: Lessons learned from SARS and MERS epidemic. Asian Pac J Allergy Immunol, v. 38, n. 1, p. 1-9, 2020.

ROCHA, Joanna de Freitas; MOTA, Erika Freitas. Imunidade contra bactérias: abordagem para o ensino remoto de imunologia. In: Almeida, D. M.; Natale, C. C.; Mello, P. S.

Imunologia na sala de aula: sequências de ensino/Immunology in the classroom: teaching sequences. São Paulo: Editora Na Raiz. 2021. Disponível em:

https://doi.org/10.5281/zenodo.5545819.

SANTOS JUNIOR, Verissimo Barros; DA SILVA MONTEIRO, Jean Carlos. Educação e covid19: as tecnologias digitais mediando a aprendizagem em tempos de pandemia. Revista Encantar-Educação, Cultura e Sociedade, v. 2, p. 01-15, 2020.

SEEMANN, Paulo Augusto Almeida. A produção de roteiros de áudio-descrição de vídeos feita por iniciantes: dificuldades comuns e sugestões para evitá-las. Revista Educação Especial, v.32, p. 1 - 22, 2019.

SEPTIMIO, Carolline; MENDES, Geovana Mendonça Lunardi; DA COSTA, Gilcilene Dias. Errância e inventividade: o (não) saber docente e os desafios da educação inclusiva. In: Educação especial e/na educação básica: entre especificidades e indissociabilidades [recurso eletrônico] / org: MENDES, G. M. L., PLETSCH, M. D., HOSTINS, R. C. L. - 1. ed. Araraquara [SP]: Junqueira \& Marin, 2019.

SERAFIM, Maria Lúcia; SOUSA, Robson P. Multimídia na educação: o vídeo digital integrado ao contexto escolar. Tecnologias digitais na educação, p. 19-50, 2011.

SILVA, Jean Carlos Souza; FALCÃO, Dayseanne de Araújo; DANTAS, Iron Macêdo. Análise psicométrica das estratégias de estudo e aprendizagem em imunologia. Investigações em Ensino de Ciências, v.26, n.1, p. 85-109, 2021. 
-Revista de Iniciação à Docência, v.6, n.2, 2021-

Publicação: dezembro, 2021 - ISSN 2525-4332

SILVA, Lara Rodrigues da. Além das limitações da visão: acessibilidade dos recursos didáticos utilizados na disciplina de Imunologia para inclusão de alunos deficientes visuais. 2020. Trabalho de Conclusão de Curso (Licenciatura em Ciências Biológicas) Universidade Federal do Ceará, Fortaleza, 2020.

SILVA, Ludmila Caroline et al. Correlação entre a exposição diária à luz azul violeta emitida por dispositivos digitais e a visão de adultos jovens. Saúde em Revista, v. 15, n. 41, p. 4755, 2015.

SOUZA, Rosana Wichineski de Lara et al. Modalidades e recursos didáticos para o ensino de biologia. Revista Eletrônica de Biologia (REB). ISSN 1983-7682, v. 7, n. 2, p. 124-142, 2014 .

SPALDING, Marianne et al. Desafios e possibilidades para o ensino superior: uma experiência brasileira em tempos de COVID-19. Research, Society and Development, v. 9, n. 8, p. e534985970-e534985970, 2020.

TREVIZANI, Lenara Patrícia, MARIN, Angela Helena. Competência emocional em professores e sua relação com tempo de docência e satisfação com o trabalho. Revista psicopedagogia, 37(112): 52-63, p. $52-63,2020$.

VARGAS, Gárdia Maria Santos. A inclusão no ensino superior: a experiência da disciplina Prática Pedagógica-Prática de Ensino de uma turma de alunos cegos e com baixa visão. Ponto de Vista: revista de educação e processos inclusivos, n. 8, p. 131-138, 2006.

ZOGZA, Vassiliki. Biology didactics: A distinct domain of educational research. In: The Future of Biology Education Research: Proceedings of the 10th Conference of European Researchers in Didactics of Biology. Haifa, Israel: Technion, p. 181-187, 2016. 